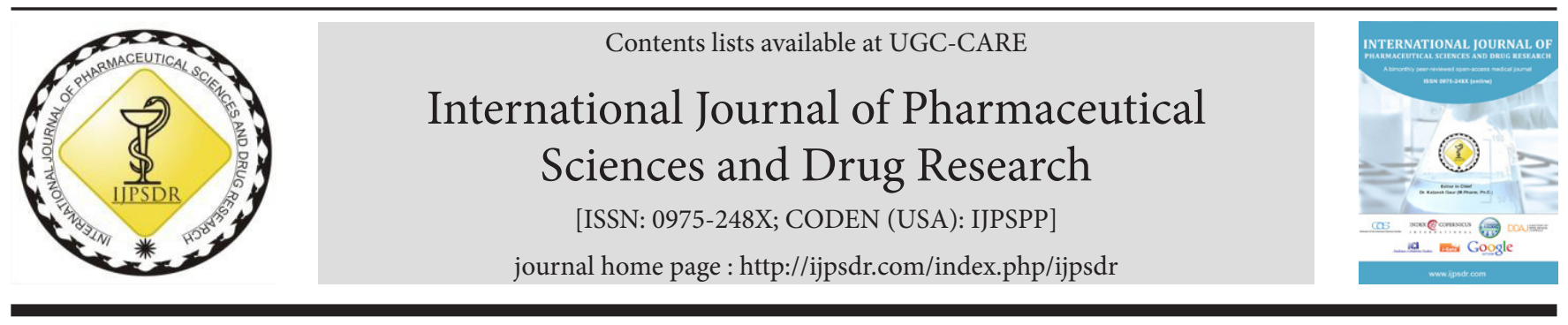

Research Article

\title{
Fluidized Hot Melt Granulation Technique: An Approach to Improve Micromeritics Properties and Dissolution Rate of Efavirenz
}

\author{
Deval J. Modi ${ }^{*}$, Pragna K. Shelat, Divyesh H. Shastri \\ Department of Pharmaceutical Sciences, K. B. Institute of Pharmaceutical Education and Research, Kadi Sarva Vishwavidyalaya, Sector-23, GH-6 Circle, \\ Gandhinagar-382023, Gujarat, India
}

\author{
A RT I C LE INFO \\ Article history: \\ Received: 29 June, 2020 \\ Revised: 22 August, 2020 \\ Accepted: 30 August, 2020 \\ Published: 30 September, 2020 \\ Keywords: \\ Efavirenz, \\ Fluidized bed granulation, \\ Fluidized hot melt granulation, \\ Meltable binder, \\ Top spray. \\ DOI: \\ 10.25004/IJPSDR.2020.120518
}

\begin{abstract}
A B S T R A C T
The fluidized hot melt granulation technique is a process by which pharmaceutical powders are efficiently agglomerated using a low melting binder. The effect of the binder properties and concentrations on agglomerate growth mechanisms were studied in this research paper, using this technique with the primary objective of improvement in the solubility and dissolution rate of efavirenz by melt-dispersion granulation employing meltable hydrophilic carrier, and then to convert the melt dispersion into flowable and compressible dispersion granules to yield a rapidly dissolving tablet formulation. The optimized concentrations of co-polymers, like polyethylene glycol (PEG) 6000, PEG 4000, gelucire 50/13, gelucire 44/14, poloxamer 188, and poloxamer 407 in different ratios (i.e., 1:1, 1:2, 1:3, and 1:4) as meltable binder along with the drug were sprayed dropwise over lactose as diluent loaded into fluid bed chamber for the preparation of the granules of efavirenz and characterized for its micromeritical properties, differential scanning calorimetry (DSC), X-ray diffraction (XRD), etc. The tablets prepared from the granules were evaluated for drug dissolution rate. The prepared granules were found to have excellent flow properties indicated by mean diameter D50:138 $\mu \mathrm{m}$, Carr's index 13.92\%, and the drug content uniformity of $98.10 \%$. XRD data exhibited a partial loss of crystallinity as indicated by significantly less intensity of efavirenz peak in the sample than pure efavirenz. Drug release from the tablet was fast found $99.12 \% \mathrm{w} / \mathrm{v}$ within 30 minutes. The absence of efavirenz endothermic peak at higher proportions of meltable binder reported by DSC data exhibited an amorphous form of efavirenz that led to complete solubilization, and thus, the faster dissolution rate of efavirenz.
\end{abstract}

\section{INTRODUCTION}

In the last two decades, there has been an increasinginterest in the solubility enhancement of active pharmaceutical ingredients, particularly on those belonging to class II of the Biopharmaceutics Classification System (BCS). Hence, the enhancement of the aqueous solubility in such a case shall lead to increased therapeutic efficacy and bioavailability. ${ }^{[6]}$ Numerous techniques and methods have been reported on how the solubility of efavirenz (EFZ) can be enhanced. Enhancement of the dissolution rate is attaining a suitable blood concentration for therapeutic effect, their dissolution rates are typically the rate-limiting step for bioavailability. Efavirenz is established in anti-HIV with poor water solubility.

Fluidized hot melt granulation (FHMG) has received considerable attention in recent years with most of these processes involving the spraying of the molten binder onto a bed of fluidized particles. In this method, the granule growth mechanism is dependent on the ratio of binder droplet size to powder particle size. Using a lower ratio led to nucleation, which then gave rise to coalescence and further granule growth (Schaefer's group). The increased granule size was influenced by the viscosity of the binder melt and by utilizing the binder properties

\footnotetext{
*Corresponding Author: Deval J. Modi

Address: K. B. Institute of Pharmaceutical Education and Research, Kadi Sarva Vishwavidyalaya, Sector-23, GH-6 Circle, Gandhinagar-382023, Gujarat, India

Email $\bowtie$ : modideval80@gmail.com

Relevant conflicts of interest/financial disclosures: The authors declare that the research was conducted in the absence of any commercial or financial relationships that could be construed as a potential conflict of interest.

Copyright (C) 2020 Deval J. Modi et al. This is an open access article distributed under the terms of the Creative Commons Attribution- NonCommercialShareAlike 4.0 International License which allows others to remix, tweak, and build upon the work non-commercially, as long as the author is credited and the new creations are licensed under the identical terms.
} 
improved the physical properties of tablets pressed from the hot melted granules. ${ }^{[9]}$

The main objective of the present research work was to improve the solubility and dissolution rate of efavirenz by melt-dispersion granulation employing meltable hydrophilic carrier and then to convert the melt dispersion into flowable and compressible dispersion granules to yield a rapidly dissolving tablet formulation.

\section{Materials AND METHODS}

\section{Materials}

Efavirenz was procured from Piramal Pharma Solution, India. Lactose monohydrate (Flowlac 100) was purchased from Meggle and extra-granular avicel PH 102 was purchased from FMC, polyplasdone XL 10 was purchased from Ashland and magnesium stearate was purchased from Ferro Synpro. The materials used were Gelucire ${ }^{\circledR}$ 50/13 or 44/14 (Gattefosse Ltd., France), PEG 6000 or 4000 (Synth Ltda., Brazil), poloxamer 407 or 188 (Synth Ltda., Brazil).

\section{Method}

\section{Solubility Study in Different Binders}

Phase solubility studies, in which excess amount of efavirenz was added to conical flasks containing different meltable binders and stirred in a water bath for one hour using a magnetic stirrer (model: 1MLH, company: Remi, country: India). Then, the content of each flask was filtered through a $0.45 \mu \mathrm{m}$ membrane and the filtrate was suitably diluted and analyzed at $247 \mathrm{~nm}$ by ultraviolet (UV) spectrophotometer.

\section{Screening of Drug to Binder Ratio}

For fluid bed processing (FBP) (Glatt ${ }^{\circledR}$-GPCP); mixtures of meltable binders in different ratios shown in Table 1, along with efavirenz were prepared and kept in a jacketed vessel to obtain the desired temperature of near melting point with continuous heating and stirring. The molten mixture was sprayed dropwise from the top over the 40\# sifted lactose monohydrate (Flowlac 100) powder loaded in a fluidized bed chamber to prepare granules. The formed granules were then rapidly cooled down to room temperature by fluidization and collected for subsequent micromeritical characterizations.

Table 1: Drug:binder ratio

\begin{tabular}{llll}
\hline S. No. & Drug & Binder & Drug:binder ratio \\
\hline 1 & Efavirenz & Gelucire 50/13 & $1: 1,1: 2,1: 3,1: 4$ \\
2 & Efavirenz & Gelucire 44/14 & $1: 1,1: 2,1: 3,1: 4$ \\
3 & Efavirenz & PEG 6000 & $1: 1,1: 2,1: 3,1: 4$ \\
4 & Efavirenz & PEG 4000 & $1: 1,1: 2,1: 3,1: 4$ \\
5 & Efavirenz & Poloxamer 407 & $1: 1,1: 2,1: 3,1: 4$ \\
6 & Efavirenz & Poloxamer 188 & $1: 1,1: 2,1: 3$ \\
\hline
\end{tabular}

\section{Preparation of Tablets}

Dried granules were sifted through 30 \# screen using a mechanical sifter and mixed with avicel PH102 (40\#), polyplasdone XL100 (40\#) in a double cone blender for 5 minutes at $10 \pm 2 \mathrm{rpm}$, and lubricated with magnesium stearate (60\#). The lubricated granules were compressed using a tablet compression machine (RIMEK $\left.{ }^{\circledR}\right)$ and evaluated for drug release and dissolution profile.

\section{Selection of appropriate Process Parameters of Fluid Bed Processing (FBP)}

The effect of critical process parameters (CPPs) on product quality (e.g., average granule size) was analyzed and control manufacturing through timely measurements of critical quality and performance attributes of in-process materials, which were modeled out with the goal of ensuring product quality as revealed, is shown in Table 2.

\section{Characterization}

\section{Micromeritical Properties}

Various micromeritical properties of granules were evaluated, i.e., bulk density (BD), tapped density (TD), compressibility index (\% CI), and Hausner's ratio.

\section{Size Analysis and Drug Content Uniformity}

The granule size distribution study carried out using a particle size analyzer (model: Mastersizer 3000 and make: Malvern) in the range of 65 to $1,200 \mu \mathrm{m}$. 10 milligrams of melt granules were added to $10 \mathrm{~mL}$ of distilled water, heated to 60 to $70^{\circ} \mathrm{C}$, and allowed to cool at room temperature. The lipid was solidified, and the drug solution was filtered through Whatman filter paper no. 1. The samples were analyzed for drug content by UV spectrophotometer (model: UV 1800 and make: Shimadzu) at $247 \mathrm{~nm}$ after suitable dilution.

\section{DSC Analysis}

DSC scans of the powdered samples were recorded using DSC (822e, Mettler Toledo) with the STARe software. All the samples were weighed (4-5 mg) and heated for a total time of 40 minutes at a scanning rate of $5^{\circ} \mathrm{C} /$ minutes under dry air $\left(\mathrm{N}_{2}\right)$ flow $(50 \mathrm{~mL} / \mathrm{min})$ at a pressure of $25 \mathrm{psi}$ between 50 and $250^{\circ} \mathrm{C}$ (furnace temperature). Aluminum pans and lids (40 $\mu \mathrm{L}$ capacity) were used in this study.

X-Ray Diffraction (XRD) Study

The XRD patterns were recorded on an X-diffractometer

Table 2: FBP limit parameter

\begin{tabular}{lll}
\hline No. & FBP parameter & Limit \\
\hline 1 & Inlet temperature & $50 \pm 10^{\circ} \mathrm{C}$ \\
2 & Outlet temperature & $40 \pm 10^{\circ} \mathrm{C}$ \\
3 & Product temperature & $30 \pm 10^{\circ} \mathrm{C}$ \\
4 & Spraying rate & $3 \mathrm{gm} / \mathrm{mL}$ \\
5 & Atomization air pressure & $2.5 \mathrm{bar}$ \\
\hline
\end{tabular}


(Phillip PW 1130/00 diffractometer, Netherlands), employing $\mathrm{CuK}_{\infty}$ radiation source operating at $30 \mathrm{~mA}$ and $40 \mathrm{kV}$. Samples were scanned from 6 to $40^{\circ} 2 \theta$ at a scanning rate of $0.02^{\circ} 2 \theta \mathrm{S}^{-1}$.

\section{Fourier Transform Infraradiation (FTIR) Study}

The FTIR spectra of the prepared formulation were recorded on Shimadzu FTIR (8400 spectrophotometer). The potassium bromide pellet method was employed, and the background spectrum was collected under an identical situation. Each spectrum was derived from single average scans collected in the region 400 to $4,000 \mathrm{~cm}^{-1}$. Spectra were analyzed by software supplied by Shimadzu.

\section{In vitro Dissolution Study}

In vitro dissolution study of efavirenz was performed on United States Pharmacopoeia (USP) type-II dissolution test apparatus in $900 \mathrm{~mL}$ of $2 \% \mathrm{w} / \mathrm{v}$ sodium lauryl sulfate (SLS) solution with constant temperature $37 \pm 0.2^{\circ} \mathrm{C}$ and speed $50 \pm 2 \mathrm{rpm}$. Aliquots were withdrawn at 10,20 , and 30 minutes time intervals and analyzed by UV-visible spectrophotometric, and the percentage release of the drug was recorded.

\section{Physical Parameters of Tablet}

The hardness and thickness of tablets were determined using a tablet hardness tester (TBH 300 MP Erweka, Germany). The friability of tablets was determined in Roche friabilator tester on 20 tablets, in the apparatus running for 4 minutes at a speed of $25 \mathrm{rpm}$. Disintegration time was determined in the water at $37^{\circ} \mathrm{C}$ by means of disintegration test apparatus with disks (ZT 74, Erweka, Germany). The time recorded was the time required for the last tablet (out of six) to disintegrate.

\section{Stability Study}

The purpose of stability testing is to provide evidence on how the quality of a drug substance or drug product varies with time under the influence of a variety of environmental factors, such as, temperature, humidity, and enables recommended storage condition, re-test periods, and shelf life to be established. Stability studies were carried out for optimized formulations. A formulation was stored at accelerated stability condition $40 \pm 2^{\circ} \mathrm{C} / 75 \pm 5 \% \mathrm{RH}$ and $25 \pm 2{ }^{\circ} \mathrm{C} / 60 \pm 5 \% \mathrm{RH}$ for an interval of 1,3 , and 6 months. Samples were withdrawn and tested with regards to the parameters, i.e., drug content and in vitro drug release.

Table 3: Solubility study in different binders

\begin{tabular}{ll}
\hline Binders & Solubility $(\mathrm{mg})$ \\
\hline PEG 6000 & $28.19 \pm 0.12$ \\
PEG 4000 & $17.12 \pm 0.26$ \\
Gelucire 50/13 & $25.49 \pm 0.1$ \\
Gelucire 44/14 & $14.56 \pm 0.31$ \\
Poloxamer 407 & $30.39 \pm 0.15$ \\
Poloxamer 188 & $34.19 \pm 0.28$ \\
\hline
\end{tabular}

\section{RESULTS AND DISCUSSION}

\section{Solubility Study in Different Binders}

The saturated solubility of efavirenz was determined by UV spectrophotometry at $247 \mathrm{~nm}$ and yielded a value of efavirenz found to be more soluble in poloxamer 188 , as shown in Table 3.

\section{Screening of Binder Concentration}

\section{Micromeritical Characterization}

All tested formulations had a Carr's index ranging from $13.92 \pm 0.17 \%$ to $25.7 \pm 0.58 \%$ and the granules obtained from batch F23 showed good micromeritical properties, i.e., Carr's index $13.92 \pm 0.17$, Hausner's ratio $1.16 \pm 0.02$, bulk density $0.439 \pm 0.05$, and tapped density $0.51 \pm 0.04$. Results of the characterization of the granules are shown in Table 4. The granulation using poloxamer 407 as a binder was not possible for two of the experimental conditions chosen for the experimental design. This was due to the high viscosity of poloxamer (POL) in the molten state.

\section{Granules Size Analysis and Drug Content Uniformity Studies}

The amount of fine powder $(<70 \mu \mathrm{m})$ and big lumps (size $>1,200 \mu \mathrm{m}$ ) are less than 2 and $6 \%$, respectively, which confirmed that the parameters selected were correct. The majority of the fraction of the granules was between the size range of 150 to $400 \mu \mathrm{m}$ and more than $50 \%$ of the granules had a size in the range of 120 to $249 \mu \mathrm{m}$. The drug content in the prepared melt granules of batches F1 to F19 was determined and found to have $98.1 \pm 1.63 \% \mathrm{w} / \mathrm{v}$, showed no or less wastage or deterioration of the drug in the melt granules formulation. The results are shown in Table 5.

\section{DSC Analysis}

The DSC curves are shown in Fig. 1. Efavirenz shows a sharp melting peak of $137.27^{\circ} \mathrm{C}$. DSC curve of dispersion at higher proportions of poloxamer 188 exhibited no drug endothermic peak. The absence of efavirenz melting endothermic in these samples due to the solubility of the drug in poloxamer 188.

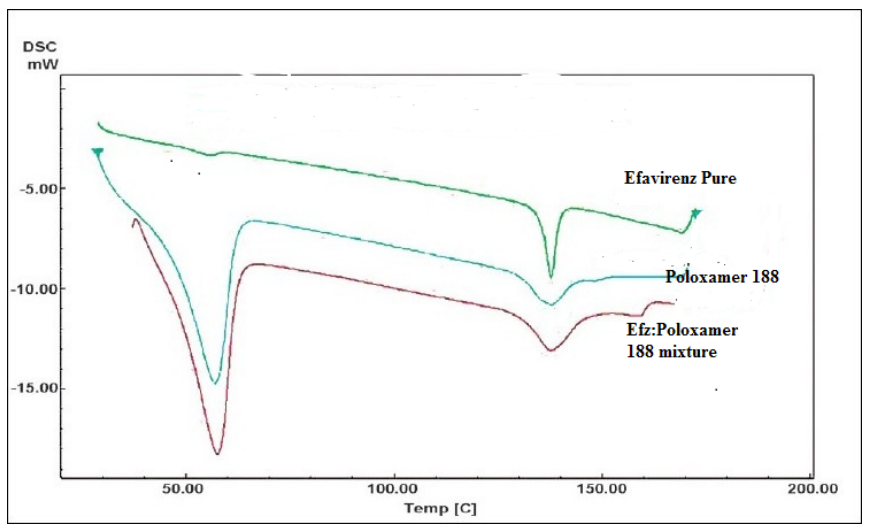

Fig. 1: DSC thermogram of A) pure drug, B) poloxamer 188, and C) physical mixture blend 
Fluidized Hot Melt Granulation to Improve Dissolution Rate of Efavirenz

Table 4: Screening of different binder ratio

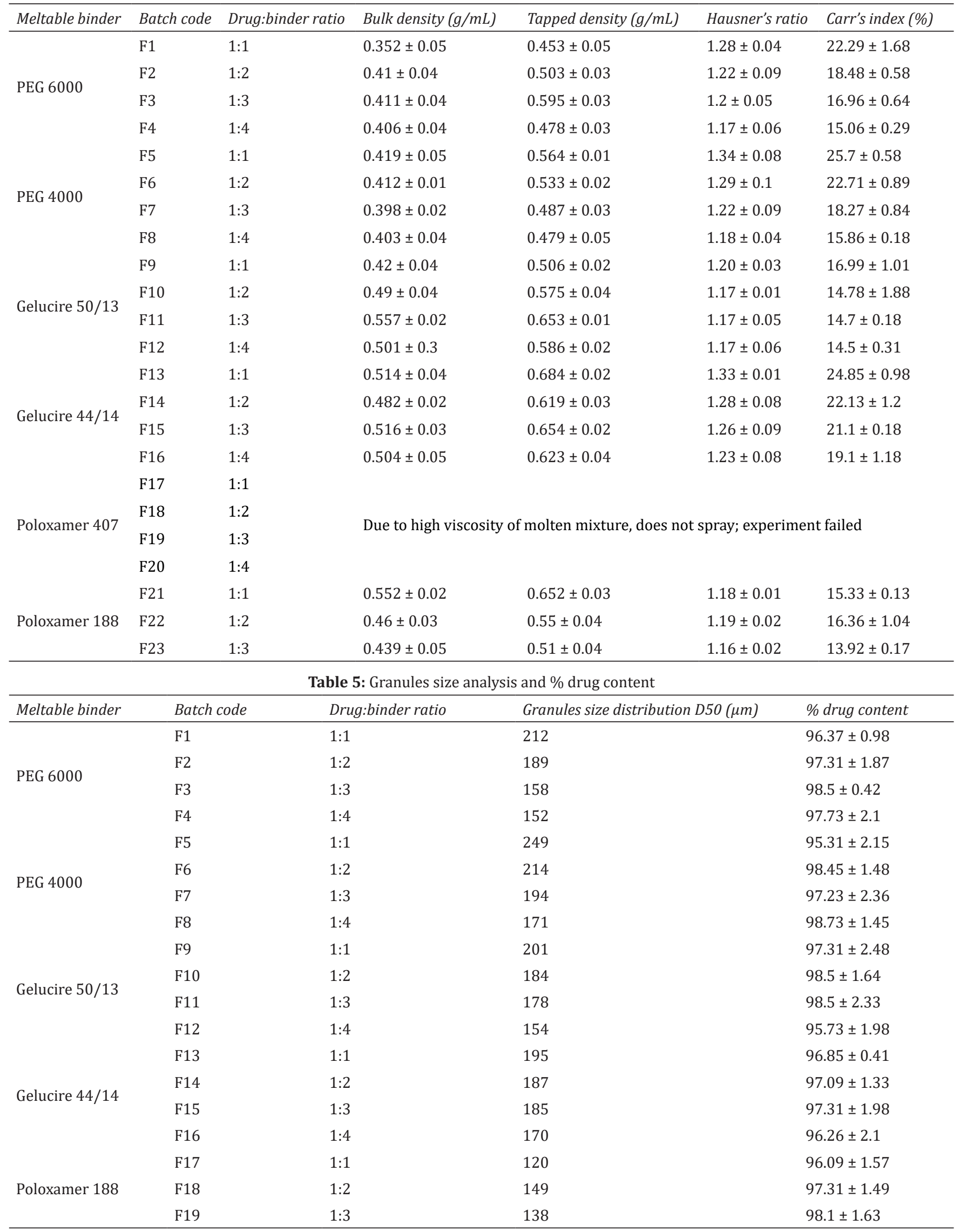




\section{X-Ray Diffraction Analysis}

The intensity of the peak efavirenz in the physical mixture (PM) dispersion sample (Fig. 2) was significantly less than of the pure drug due to partial loss of crystallinity. This suggested that the drug in PM dispersion is amorphous as compared to the pure drug. Increase dissolution of the drug was observed an amorphous form dissolve at a faster rate than crystalline materials.

\section{FTIR Studies}

All major peaks of EFZ and poloxamer 188 were observed in Fig. 3 and were retained in drug:POL 188 (1:3) meltable mixture, which clearly indicated that no interaction occurred between pure drug and poloxamer 188.

\section{In vitro Dissolution Studies}

The dissolution profile of all formulations are shown in Table 6 and Fig. 4. Fig. 4 indicated that the melt granules formulation 1:3 of efavirenz:poloxamer 188 gives a fast dissolution rate of $99.12 \pm 1.63 \%$ in 30 minutes, as compared to other meltable binders. The melt granulation technique has improved the dissolution rate of efavirenz to a greater extent.

\section{Physical Parameters of Tablet}

Tablets obtained from granules prepared by the FHMG technique have shown faster disintegration time, as shown in Table 7. Faster disintegration corresponded to the lower hardness of the tablet. Disintegration time (DT) of formulation batch F19 containing drug:poloxamer 188 ratio of 1:3 have shown less than 4 minutes.

The hardness of the tablets was in the range of 8 to $14 \mathrm{~kg} / \mathrm{cm}^{2}$. This reveals that the required compressibility was imparted by avicel PH102. Poloxamer 188 is a waxy material and tends to stick to the punches during compression. This problem was resolved by incorporating magnesium stearate. Despite the corresponding lower hardness, these tablets were more resistant to mechanical stress as demonstrated in the friability test. Friability values were in the range of 0.12 to $0.28 \%$, which ensured no loss of materials from the surface or edge of tablets. This may be attributed to the waxy nature of poloxamer 188. All the formulations passed the weight variation test, which was an indication of good flowability.

\section{Stability Studies}

The optimized formulation batch F19 was evaluated for stability studies as per International Council for

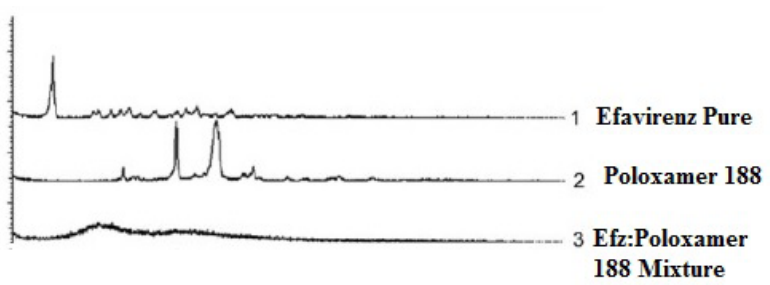

Fig. 2: X-ray diffraction spectra of efavirenz pure (1), poloxamer 188 (2), and 1:3 ratio dispersion (3)

Table 6: \% drug release of formulation

\begin{tabular}{|c|c|c|c|c|c|}
\hline \multirow[b]{2}{*}{ Meltable binder } & \multirow[b]{2}{*}{ Batch code } & \multirow[b]{2}{*}{ Drug:binder ratio } & \multicolumn{3}{|c|}{ Dissolution (\%) in minutes } \\
\hline & & & 10 & 20 & 30 \\
\hline \multirow{4}{*}{ PEG 6000} & $\mathrm{~F} 1$ & $1: 1$ & $10.15 \pm 1.25$ & $21.59 \pm 1.19$ & $32.15 \pm 1.47$ \\
\hline & $\mathrm{F} 2$ & $1: 2$ & $22.15 \pm 1.72$ & $36.52 \pm 1.87$ & $49.1 \pm 1.17$ \\
\hline & F3 & $1: 3$ & $30.18 \pm 1.08$ & $41.26 \pm 2.09$ & $52.16 \pm 0.18$ \\
\hline & $\mathrm{F} 4$ & $1: 4$ & $36.58 \pm 1.29$ & $58.12 \pm 1.44$ & $71.59 \pm 2.12$ \\
\hline \multirow{4}{*}{ PEG 4000} & F5 & $1: 1$ & $10.21 \pm 2.41$ & $20.78 \pm 1.4$ & $23.13 \pm 1.5$ \\
\hline & F6 & $1: 2$ & $14.78 \pm 1.45$ & $29.84 \pm 1.51$ & $35.85 \pm 2.13$ \\
\hline & F7 & $1: 3$ & $16.87 \pm 1.79$ & $33.52 \pm 1.25$ & $51.19 \pm 2.45$ \\
\hline & F8 & $1: 4$ & $23.69 \pm 1.49$ & $46.98 \pm 1.11$ & $70.79 \pm 1.84$ \\
\hline \multirow{4}{*}{ Gelucire 50/13 } & F9 & $1: 1$ & $21.58 \pm 1.14$ & $36.98 \pm 1.41$ & $57.1 \pm 1.78$ \\
\hline & F10 & $1: 2$ & $28.56 \pm 1.52$ & $41.25 \pm 1.94$ & $62.58 \pm 2.03$ \\
\hline & F11 & $1: 3$ & $31.29 \pm 1.04$ & $49.82 \pm 1.74$ & $69.48 \pm 2.51$ \\
\hline & F12 & $1: 4$ & $39.62 \pm 1.56$ & $59.84 \pm 1.58$ & $84.15 \pm 2.14$ \\
\hline \multirow{4}{*}{ Gelucire 44/14 } & F13 & $1: 1$ & $17.51 \pm 2.1$ & $25.31 \pm 1.45$ & $35.89 \pm 1.23$ \\
\hline & F14 & $1: 2$ & $19.2 \pm 2.13$ & $35.18 \pm 1.56$ & $49.04 \pm 1.44$ \\
\hline & F15 & $1: 3$ & $23.51 \pm 1.87$ & $46.62 \pm 1.48$ & $68.25 \pm 2.15$ \\
\hline & F16 & $1: 4$ & $27.19 \pm 1.48$ & $51.89 \pm 1.94$ & $74.85 \pm 1.64$ \\
\hline \multirow{3}{*}{ Poloxamer 188} & F17 & $1: 1$ & $39.65 \pm 1.36$ & $51.12 \pm 1.32$ & $59.23 \pm 1.54$ \\
\hline & F18 & $1: 2$ & $52.18 \pm 1.68$ & $65.25 \pm 1.92$ & $74.69 \pm 2.86$ \\
\hline & F19 & $1: 3$ & $59.23 \pm 1.97$ & $74.69 \pm 1.91$ & $99.12 \pm 1.63$ \\
\hline
\end{tabular}


Fluidized Hot Melt Granulation to Improve Dissolution Rate of Efavirenz

Table 7: Physical parameter of tablet

\begin{tabular}{|c|c|c|c|c|c|c|}
\hline Meltable binder & Batch code & Drug:binder ratio & Hardness $\left(\mathrm{kg} / \mathrm{cm}^{2}\right)$ & Weight (mg) & Friability (\%) & $\begin{array}{l}\text { Disintegration } \\
\text { time (minute) }\end{array}$ \\
\hline \multirow{4}{*}{ PEG 6000} & $\mathrm{~F} 1$ & $1: 1$ & $11 \pm 1.2$ & $512 \pm 0.9$ & 0.181 & 7.1 \\
\hline & F2 & $1: 2$ & $10 \pm 1.6$ & $514 \pm 1.1$ & 0.185 & 6.9 \\
\hline & F3 & $1: 3$ & $10 \pm 1.8$ & $511 \pm 0.4$ & 0.211 & 6.4 \\
\hline & $\mathrm{F} 4$ & $1: 4$ & $9 \pm 1.1$ & $512 \pm 0.6$ & 0.139 & 6.6 \\
\hline \multirow{4}{*}{ PEG 4000} & F5 & $1: 1$ & $14 \pm 1.3$ & $514 \pm 1.2$ & 0.218 & 9.8 \\
\hline & F6 & $1: 2$ & $13 \pm 1$ & $516 \pm 1$ & 0.211 & 8.1 \\
\hline & F7 & $1: 3$ & $11 \pm 1.4$ & $513 \pm 0.8$ & 0.214 & 8.6 \\
\hline & F8 & $1: 4$ & $10 \pm 1$ & $514 \pm 0.1$ & 0.218 & 6.2 \\
\hline \multirow{4}{*}{ Gelucire 50/13 } & F9 & $1: 1$ & $10 \pm 1.1$ & $510 \pm 0.6$ & 0.135 & 5.3 \\
\hline & F10 & $1: 2$ & $9 \pm 1.3$ & $512 \pm 0.8$ & 0.132 & 5 \\
\hline & F11 & $1: 3$ & $9 \pm 1.2$ & $514 \pm 1.2$ & 0.119 & 4.9 \\
\hline & F12 & $1: 4$ & $8 \pm 1.7$ & $516 \pm 1$ & 0.127 & 4.5 \\
\hline \multirow{4}{*}{ Gelucire 44/14 } & F13 & $1: 1$ & $11 \pm 1.3$ & $513 \pm 0.6$ & 0.214 & 5.3 \\
\hline & F14 & $1: 2$ & $9 \pm 1$ & $515 \pm 0.9$ & 0.225 & 6.1 \\
\hline & F15 & $1: 3$ & $9 \pm 1.7$ & $513 \pm 0.5$ & 0.286 & 5.9 \\
\hline & F16 & $1: 4$ & $9 \pm 1.9$ & $513 \pm 0.9$ & 0.245 & 7.2 \\
\hline \multirow{3}{*}{ Poloxamer 188} & F17 & $1: 1$ & $9 \pm 1.1$ & $515 \pm 0.9$ & 0.131 & 4.5 \\
\hline & F18 & $1: 2$ & $8 \pm 1.6$ & $517 \pm 1.1$ & 0.128 & 4.3 \\
\hline & F19 & $1: 3$ & $8 \pm 1.2$ & $514 \pm 0.5$ & 0.125 & 4 \\
\hline
\end{tabular}

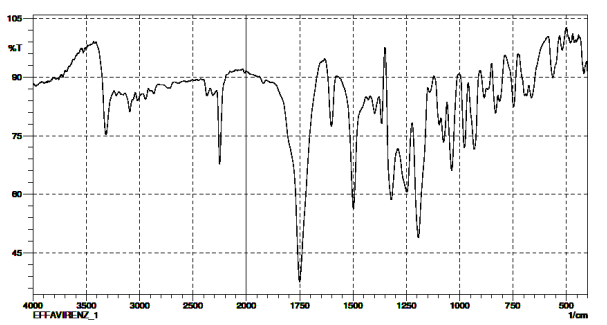

Fig. 3: FTIR of pure drug efavirenz (A), poloxamer 188 (B), and drug:poloxamer 188 (1:3) meltable mixture (C)

Harmonisation (ICH) guidelines at $40 \pm 2^{\circ} \mathrm{C} / 75 \pm 5 \% \mathrm{RH}$ and $25 \pm 2{ }^{\circ} \mathrm{C} / 60 \pm 5 \% \mathrm{RH}$ conditions and monitored for drug content and in vitro drug release study at 1,3 , and 6 months. Table 8 indicated the results of the stability studies revealed no significant variation in drug content uniformity and in vitro drug release profile up to 6 months.

\section{Comparative In vitro Drug Release Profile Study}

The optimized formulation batch F19 prepared through the FHMG technique, using poloxamer 188 in the drug:binder ratio of 1:3 evaluated for in vitro drug release profile study and compared with the generic marketed formulation of a tablet containing $50 \mathrm{mg}$ efavirenz, using $900 \mathrm{~mL}$ of $2 \%$ SLS solution for 30 minutes. The drug release rate of efavirenz from optimized formulation batch F19 was 99.12 $\% \mathrm{w} / \mathrm{v}$, as compared with $88.46 \% \mathrm{w} / \mathrm{v}$ efavirenz release from marketed $50 \mathrm{mg}$ tablet at the end of 30 minutes, as shown in Fig. 5, which clearly indicated that the optimized formulation could be used to improve the therapeutic effect of efavirenz.

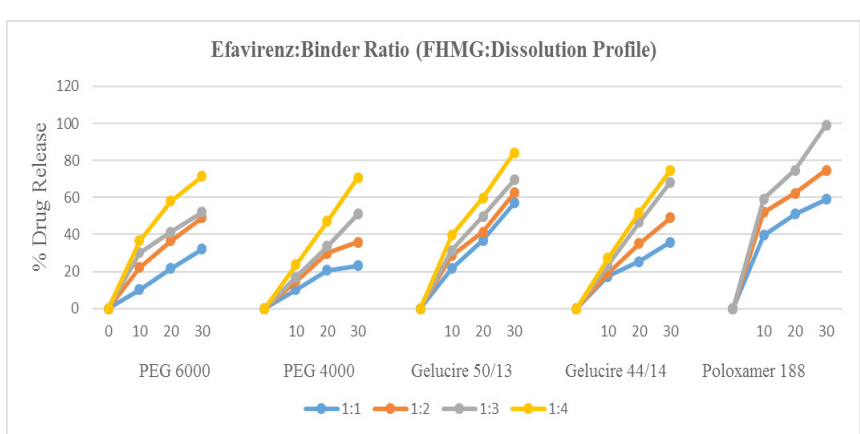

Fig. 4: Dissolution profile of drug:binder ratio

\section{DISCUSSION}

The granules obtained in all experimental conditions have shown adequate flow properties. The granule size (D50) showed moderate size enlargement indicating binder coating predominated over agglomeration. Dispersions granules of efavirenz prepared with different ratios of melted binders, i.e., gelucire 50/13 or $44 / 14$, PEG6000 or 4000 , and poloxamer PF188 or 
Deval J. Modi et al.

Table 8: Stability studies

\begin{tabular}{|c|c|c|c|c|c|c|c|c|}
\hline \multirow{3}{*}{$\begin{array}{l}\text { Parameters } \\
\text { Duration }\end{array}$} & \multicolumn{8}{|c|}{ Optimized formulation: F19 } \\
\hline & \multicolumn{4}{|c|}{$40 \pm 2^{\circ} \mathrm{C} / 75 \pm 5 \% R H$} & \multicolumn{4}{|c|}{$25 \pm 2^{\circ} \mathrm{C} / 60 \pm 5 \% R H$} \\
\hline & Initial & $1 M$ & $3 M$ & $6 M$ & Initial & $1 M$ & $3 M$ & $6 M$ \\
\hline Assay & $98.01 \pm 1.53$ & $97.15 \pm 1.48$ & $98.11 \pm 1.15$ & $98.09 \pm 1.05$ & $98.01 \pm 1.53$ & $98.22 \pm 1.08$ & $97.46 \pm 1.6$ & $97.33 \pm 1.12$ \\
\hline Dissolution & \multicolumn{8}{|c|}{ \% drug release } \\
\hline 10 minutes & $59.23 \pm 1.97$ & $58.12 \pm 1.71$ & $57.36 \pm 1.15$ & $58.16 \pm 1.03$ & $59.23 \pm 1.97$ & $55.11 \pm 1.78$ & $56.76 \pm 1.46$ & $55.33 \pm 1.05$ \\
\hline 20 minutes & $74.69 \pm 1.91$ & $75.34 \pm 1.04$ & $73.01 \pm 1.84$ & $74.66 \pm 1.14$ & $74.69 \pm 1.91$ & $75.17 \pm 1.41$ & $74.02 \pm 1.3$ & $75.19 \pm 1.01$ \\
\hline 30 minutes & $99.12 \pm 1.63$ & $98.19 \pm 1.16$ & $97.31 \pm 2.1$ & $98.56 \pm 1.21$ & $99.12 \pm 1.63$ & $97.99 \pm 1.78$ & $98.08 \pm 1.4$ & $98.14 \pm 1.16$ \\
\hline
\end{tabular}

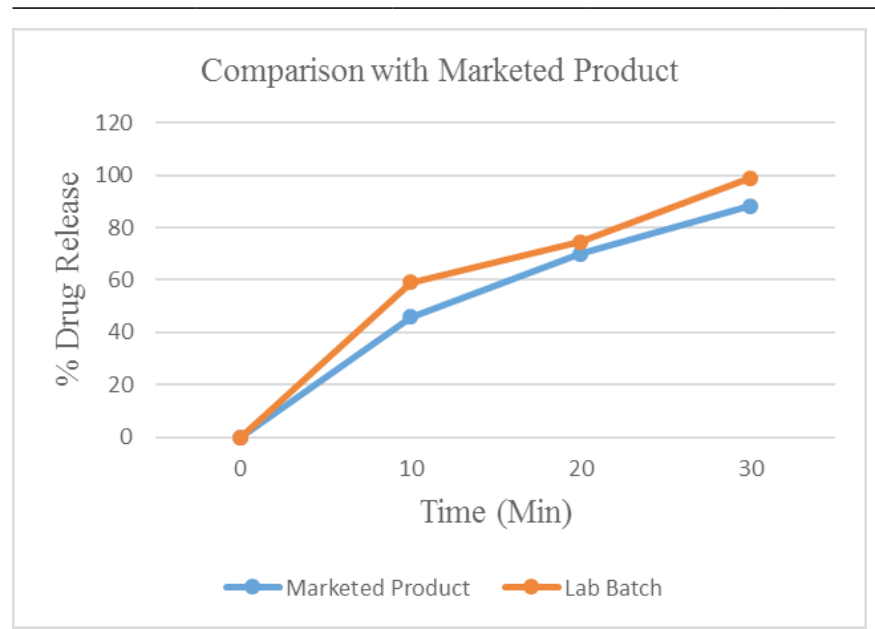

Fig. 5: Comparative in vitro drug dissolution study lab batch (orange line) and marketed sample (blue line)

PF407, by melting method shown to have good flow properties, increased saturation solubility of the drug, and in vitro dissolution rates and based on micromeritical properties and drug release profile studies. Formulation batch F19 containing drug:poloxamer 188 in the ratio of 1:3 was selected for preparation of the tablet formulation and further studies. After characterization of dispersion granules by DSC, XRD, and FTIR study, a decreased crystallinity, as well as, the surface morphology of the polymeric particles explained the enhanced solubility and improved dissolution rate of efavirenz. Thus, the dispersion granules can be utilized successfully to enhance the water solubility of poorly water-soluble drugs.

\section{CONCLUSION}

The granulation process in a fluidized bed using the FHMG technique proved to be an excellent option for pharmaceutical granulation for the solubility improvement and dissolution enhancement of poorly soluble drugs.

\section{ACKNOWLEDGEMENT}

The authors are highly thankful to the K. B. Institute of Pharmaceutical Education and Research, KSV, for providing facilities and guidance for the research.

\section{REFERENCES}

1. Sruti J, Patra CN, Swain S, Panigrahi KC, Patro AP, Beg S, et al. Improvement in the dissolution rate and tableting properties of cefuroxime Axetil by melt-granulated dispersion and surface adsorption. Acta Pharma Sinica B. 2013;3(2):113-122.

2. Kalra K, Sharma S, Jain DA. Enhancement of solubility and dissolution rate of rifapentine by melt granulation technique. Int. J Pharm Life Sci. 2012;3(3):1503-1506.

3. Shimpi S, Chauhan B, Mahadik KR, Paradkar A. Preparation and evaluation of diltiazem hydrochloride-Gelucire 43/01 floating granules prepared by melt granulation. AAPS Pharm Sci Tech. 2004 Jul 12;5(3):e43.

4. Tayel SA, Soliman II, Louis D. Formulation of ketotifen fumarate fast-melt granulation sublingual tablet. AAPS PharmSciTech. 2010 Jun;11(2):679-685.

5. Kraciuk R, Sznitowska M. Effect of different excipients on the physical characteristics of granules and tablets with carbamazepine prepared with polyethylene glycol 6000 by fluidized hot-melt granulation (FHMG). AAPS PharmSciTech. 2011 Dec;12(4):1241-1247.

6. Mukharya A. Development and scale-up of SD-FBP formulation technology in line with parametric QbD. Res J Pharm Sci 2012; 1(1):1-21.

7. Patel K, Prasad RK, Bajpai M. Enhancement of dissolution rate of domperidone using melt granulation technique. Scholar Res Lib. 2011;3(2):25-33.

8. Tandel H, Shah D, Vanza J, Jani P. Formulation development and in vitro/ex vivo assessment of mucoadhesive microemulsion for nasal delivery of centrally acting drug modafinil. Ind. Journal Novel Drug Delivery. 2016;8(2):72-92.

9. Mothilal M, Harish Kumar A, V Manasa, V Manimaran. Formulation and evaluation of modafinil fast dissolving tablets by sublimation technique. J Chem Pharm Sci. 2013;6(3):147-154.

10. Avachat AM, Parpani SS. formulation and development of bicontinuous nanostructured liquid crystalline particles of efavirenz. Colloids surf Bio interfaces. 2015;126:87-97.

11. Gaur PK, Mishra S, Bajpai M, Mishra A. Enhanced oral bioavailability of efavirenz by solid lipid nanoparticles: in vitro drug release and pharmacokinetics studies. Biomed Res Int. 2014;2014:363404.

12. Kotta S, Khan AW, Ansari SH, Sharma RK, Ali J. Anti HIV nanoemulsion formulation: optimization and in vitro-in vivo evaluation. Int J Pharm. 2014 Feb 28;462(1-2):129-134.

13. Patel GV, Patel VB, Pathak A, RajputSJ. Nanosuspension of efavirenz for improved oral bioavailability: formulation optimization, in vitro, in situ, and in vivo evaluation. Drug Dev Ind Pharm. 2014 Jan;40(1):80-91.

14. Singh A, Majumdar S, Deng W, Mohammed NN, Chittiboyina AG, Raman V, et al. Development and characterization of taste masked efavirenz pellets utilizing hot melt extrusion. J Drug Deliv Sci Technol. 2013;23(2):157-163.

15. Koh PT, Chuah JN, Talekar M, Gorajana A, Garg S. Formulation development and dissolution rate enhancement of efavirenz by solid dispersion systems. Indian J Pharm Sci. 2013 May;75(3):291-301. 